\title{
Growth in Grocery Retailing in India-Competitive Landscape of Modern vis-à-vis Traditional Grocers
}

\author{
N. Meena Rani ${ }^{1 *}$ and K. Ramachandra² \\ ${ }^{1}$ Xavier Institute of Management and Entrepreneurship, Bangalore, India \\ ${ }^{2}$ Department of Commerce and Management, Maharani College of Arts, \\ Commerce and Management for Women, Bangalore, India
}

\begin{abstract}
As India witnessed surge of modern retail format over the last decade, significant developments have taken place in its retail landscape. The authors felt it appropriate to check the reality at ground level to ascertain the truth in earlier projections or perceptions towards the modern vis a vis traditional grocery retailing. Hence a study was undertaken, largely relying on secondary data, to identify key trends which in turn would provide critical insights to the academicians, researchers and policy makers. The analysis was done for a review period from 2008-13 and forecast period from 2013-18. Key findings include a robust growth in terms of number of outlets and turnover of both modern and traditional formats during review period. The forecast seems to be more promising for modern retailers than it is for the traditional players. As the customer are getting more discerning, and strive to get value for money, convenience and product variety, the modern retailer should leave no room for complacency to meet the growing and varying needs of the consumers. The traditional mom and pop stores need to go for substantial makeover to remain relevant and a reckoning force in the booming sphere.
\end{abstract}

Keywords: Grocery Retailing, Modern Retailing, Mom and Pop Stores and Traditional Retailing

\section{Introduction}

Grocery retailing thrives, and has been interwoven into the Indian social fabric since time immemorial. It served the needy consumers through diverse routes and platforms such as neighborhood mom and pop stores, village marketsand the like. It facilitated the exchange of goods and services for money and largely remained unorganized and unregulated. India has been a nation of shopkeepers-around 14 million retailers more retail shops than the rest of the world put together (Juyal S. A., 2012). However the retailing in new millennium stands as an exciting experience to the consumer on the one side and heralding new vistas of opportunities and imposing huge challenges to the retailers on the other side. Retailing in India has been growing at a frenetic pace over the past decade.

More importantly it has witnessed rapid changes in terms of the retail mix- the quality and scale of retailing, the varieties of retail formats and also changes in consumer preferences and shopping habits (Richa, 2011). Concerns were raised that the growth of modern retailing may have an adverse effect on small retailers.

\section{Review of Literature}

Available literature provides contrasting perspectives; it supports in some ways and contradicts in many

*Email: meenasrinivas@rediff.com 
ways the view that modern and traditional grocers can harmoniously coexist and supplement each other in meeting the rising consumer demand for quality grocery and food items at competitive prices(Kalhan, 2007; Vijayakumar, 2008; Mathew, et al 2008; Shaik, 2009). Fernandes et al (2000) opined that liberalization in India had opened up the country's markets to larger retailers and foreign companies, thus increasing the number of choices available to Indian consumers. The companies are increasingly building their supply chains in India and working to understand the Indian market. Batt and Cadilhon (2007) reported that the retailing of grocery and fresh produce in modern format is rapidly evolving in many developing countries such as Kenya Brazil China and the like and making inroads into India. Vijay (2007) observed that the retail institutions play a crucial role in attracting and satisfying target customers. The diversity and changing nature of society has compelled retailers to change their store formats to provide a complete shopping experience to customers. Kalhan (2007) found a decline in sales of groceries fruits and vegetables processed foods garments shoes electronic and electrical goods in the small retail outlets where large retail stores have come up in Mumbai. Vijay Kumar et al (2008) outline the concerns about the entry of modern retailers in the Indian food sector however it was concluded that though theconcerns are valid there are more winners than losers in the process.

Mathew Joseph et al (2008) found that unorganised retailers in the locality of organised retailers faced a decline in sales and profit in the initial years; the adverse impact however weakens over the time. Shankar \& Priya (2009) contend that corporate food provision will accelerate many key elements of India's agricultural crisis rather than being a panacea for Indian agriculture. Shaik (2009) contends that the modernization of the Indian retail sector is being reflected in growth in sales of supermarkets department stores and hypermarkets. The author shares the concerns that existence of local grocery shops, ownermanned general stores, paan/beedi shops, convenience stores and handcart pavement vendors, small scale and rural vendors would be threatened. Sadaf \& Shyama (2010) opined that the whole concept of shopping has altered with a movement from the unorganised to the organised sector and dynamic consumer buying behavior is ushering in a revolution in shopping in India. Mandhachitara \& Santimauro (2011) examined how the traditional form of groceryretailing in Bangkok, Thailand enjoyed its legislative protection from the modern retail formats, which was eventually withdrawn due to pressure from the US'trade representatives and the World Trade Organization in 1990. It was found that half of the traditional outlets were closed down due to massive introduction of hypermarkets and convenience stores by 2010 while the rest of the stores survived by intra-innovation. Richa (2011) found that Most of the grocery stores turnover had decreased due to the opening of modern grocery stores in the vicinity of kirana (mom and pop) stores in Kota city and the impact was more adverse where the distance was shorter.

Goswami (2009) reviewed literature on grocery retailingand found mixed evidence on the impact of modern grocery retailers over the traditional units. The author's key findings have been discussed below:

Although traditional retail currently constitutes over 95 per cent of the total sales in the country smaller kiranas(small mom and pop stores) that are unable to compete with new age retailers in terms of variety and scale have begun losing volume in several parts of the country (Vijayraghavan and Ramsurya, 2007). Internationally while some studies suggest that large scale retailers like Wal-Mart are responsible for widespread closings of mom \& pop stores (Wal-Mart Watch, 2005; Basker, 2005) and question whether cost to communities in terms of labor displacements and higher poverty offsets against benefits of lower prices and greater convenience (Goetz and Swaminathan, 2006) other studies suggest that the process of creative destruction unleashed by Wal-Mart has had no statistically significant long-run impact on the overall size and profitability of the small business sector in the United States (Sobel and Dean, 2006). In India modern trade or organized retailing already account for 30 to 40 percent of grocery sales in the top 6-7 cities of the country (Kakkar, 2008). As pointed out by Sanghavi (2007) so far retailers who focused on developing only 
supply-side efficiencies in terms of reaching retail productivity targets need to think about demand-side efficiencies in terms of satisfaction of customers' needs in order to optimize business performance. It is important to identify efficiency levels of the various dimensions of satisfaction of customers' needs that directly link to measures of specific firm outputs that firms intend to maximize in addition to supply side efficiencies (Blose et al, 2005).

As it has been over a decade since modern retailing started to make inroads into the Indian market, the time is ripe for taking up a reviewat pan India level to check the ground realities as against the earlier projections or perceptions towards the modern vis-a-vis traditional grocery retailing. So the authors thought it pertinent to take stock of the situationto identify key trends, which in turn would provide critical insights to the academicians, researchers and policy makers.

\section{Research Design}

The Indian retail industry witnessed high growth over the last decade with a noticeable shift towards modern retailing. Modern trade includes supermarkets, hypermarkets and other organized retail outlets while much smaller grocery stores are classified under traditional channels. The foray of corporate entities into grocery retailing has been much debated in the recent past in view of its pros and cons. The contentions of the advocates and contenders of modern grocery retailing provide a divergent perspective and a reality check at the ground level provides a more realistic scenario and understanding of the issue. Hence the present study attempts to analyse the pattern of grocery retailing in India from reliable secondary data. The research was descriptive in nature and sought to understand the competitive positioning of modern vis a vis traditional grocery retailers in India by reviewing the performance in the last 5 years, that is from 2008-2013, and analyzing the forecast from 2013 to 2018 . Factors that contributed to the growth of modern grocery retailing and the dynamics that ensure sustainability of the traditional format were discussed. It is focused on the grocery retail business and provides a historical as well as futuristic perspective to academics as well as practitioners.

\section{Growth in Grocery Retailing}

Grocery and food retailing in modern format has attained a promising size which is bound to grow manifold in the coming years. The food industry is a significant part of the Indian economy with contribution of about 30 percent of the consumer wallet (Earnst \& Young, 2009).

Table 1(A) shows the phenomenal growth of grocery retailing in India during 2008-2013 in terms of value $(69 \%)$, whereas the rates of growth in number of outlets and retail space stood at $3.1 \%$ and $4.8 \%$ respectively. The forecast from 2013 to 2018 shown in Table 1(B)

Table 1(A). Grocery Retailers: Value Sales Outlets and Selling Space 2008-2013

\begin{tabular}{lcccccc}
\hline & 2008 & 2009 & 2010 & 2011 & 2012 & 2013 \\
\hline Value sales in Rsbn & 9575.3 & 10630.6 & 11830.1 & 13132.5 & 14584.0 & 16171.8 \\
Outlets in '000 & 12058.8 & 12163.1 & 12236.9 & 12303.5 & 12365.9 & 12432.5 \\
Selling Space mnsq $\mathrm{m}$ & 460.6 & 463.0 & 466.3 & 470.0 & 476.2 & 483.1 \\
\hline
\end{tabular}

Table 1(B). Grocery Retailers Forecasts: Value Sales Outlets and Selling Space 2013-2018

\begin{tabular}{lcccccc}
\hline & 2013 & 2014 & 2015 & 2016 & 2017 & 2018 \\
\hline Value sales in Rsbn & 16171.8 & 16452.5 & 16596.3 & 16708.2 & 16784.9 & 16821.1 \\
Outlets in '000 & 12432.5 & 12496.3 & 12556.8 & 12615.2 & 12670.6 & 12724.7 \\
Selling Space mnsq m & 483.1 & 490.5 & 498.7 & 508.0 & 518.6 & 530.5 \\
\hline $\begin{array}{l}\text { Source: http://www.euromonitor.com/grocery-retailers-in-india/reportMay2015 } \\
\text { International from trade }\end{array}$ & associations & trade & Euromonitor \\
sourcesMay 2015 & & & & & &
\end{tabular}


indicates that the sector would reach to its potential and hardly any major growth is predicted with respect to sales value and number of outlets. However selling space is expected to increase by $9.8 \%$ which can partly be attributed to the modern retailers' inclination to provide better quality shopping experience to the customersand the entry of new players in to the sector.

\section{Modern vis-à-vis Traditional Grocery Retailing-Competitive Positioning}

Table 2(A) shows the growth in grocery sales during the review period from 2008-2013 across modern vis a vis traditional formats which stood at $76.2 \%$ and $68 \%$ respectively, where the latter is not much lagging behind the former. Within modern format, it is the hypermarket category that had posted impressive growth of $186 \%$ followed by about $53 \%$ rise in sales of supermarkets during the study period. It may be attributed to the rising consumer preference towards wholesome shopping experience which can well be facilitated by hypermarkets. The hypermarket is considered as a catalyst and a symbol of retail change in Malaysia (HP Holsi, 2009).

The projections for 2013- 2018 in Table 2(B) suggest a negative sentiment to the traditional retailers as the value in forecast period slightly comes down, whereas the modern grocers expected to garner about 1.75 times more revenue compared to the review period. The pro-

Table 2(A). Sales in Grocery Retailers by Channel: Value 2008-2013

\begin{tabular}{lcccccc}
\hline Retail format & \multicolumn{7}{c}{ Retail value Rs billion excluding sales tax } \\
\cline { 2 - 7 } & 2008 & 2009 & 2010 & 2011 & 2012 & 2013 \\
\hline Modern Grocery Retailers & 163.0 & 138.4 & 174.0 & 197.3 & 236.2 & 287.2 \\
- Convenience Stores & 11.2 & 11.1 & 14.4 & 14.1 & 15.2 & 17.2 \\
- Forecourt Retailers & 1.4 & 1.4 & 1.3 & 1.6 & 1.7 & 1.9 \\
-- Chained Forecourt Retailers & 1.4 & 1.4 & 1.3 & 1.6 & 1.7 & 1.9 \\
- Hypermarkets & 52.5 & 63.0 & 83.6 & 92.6 & 116.6 & 150.0 \\
- Supermarkets & 97.9 & 62.9 & 74.6 & 88.9 & 102.7 & 118.1 \\
Traditional Grocery Retailers & 9412.3 & 10492.2 & 11656.2 & 12935.2 & 14347.8 & 15884.6 \\
- Food/Drink/Tobacco Specialists & 1435.9 & 1593.8 & 1777.1 & 1999.3 & 2289.2 & 2660.0 \\
- Independent Small Grocers & 7669.1 & 8551.0 & 9483.1 & 10478.8 & 11526.7 & 12610.2 \\
- Other Grocery Retailers & 307.4 & 347.3 & 396.0 & 457.2 & 532.0 & 614.4 \\
\hline
\end{tabular}

Table 2(B). Forecast Sales in Grocery Retailers by Channel: Value 2013-2018

\begin{tabular}{lcccccc}
\hline \multirow{2}{*}{ Retail format } & \multicolumn{5}{c}{ Retail value Rs billion excluding sales tax } \\
\cline { 2 - 7 } & 2013 & 2014 & 2015 & 2016 & 2017 & 2018 \\
\hline Modern Grocery Retailers & 287.2 & 318.5 & 351.7 & 392.2 & 441.5 & 501.9 \\
- Convenience Stores & 17.2 & 18.1 & 18.9 & 19.7 & 20.4 & 21.0 \\
- Forecourt Retailers & 1.9 & 1.9 & 1.9 & 1.9 & 1.9 & 2.0 \\
-- Chained Forecourt Retailers & 1.9 & 1.9 & 1.9 & 1.9 & 1.9 & 2.0 \\
- Hypermarkets & 150.0 & 165.0 & 183.4 & 210.3 & 247.2 & 298.4 \\
- Supermarkets & 118.1 & 133.4 & 147.4 & 160.4 & 172.0 & 180.6 \\
Traditional Grocery Retailers & 15884.6 & 16134.1 & 16244.6 & 16316.0 & 16343.4 & 16319.1 \\
- Food/Drink/Tobacco Specialists & 2660.0 & 2828.8 & 2966.0 & 3084.6 & 3185.8 & 3275.1 \\
- Independent Small Grocers & 12610.2 & 12658.9 & 12602.5 & 12528.2 & 12432.0 & 12303.2 \\
- Other Grocery Retailers & 614.4 & 646.4 & 676.1 & 703.1 & 725.6 & 740.9 \\
\hline $\begin{array}{l}\text { Source:http:/www.euromonitor.com/grocery-retailers-in-india/reportMay2015 } \\
\text { trade associations trade press company research trade interviews trade sources }\end{array}$ & & & & & Euromonitor & International from \\
Note: Forecast value data in constant terms & & & & &
\end{tabular}


jected decline in revenue to the independent grocers could be a cause of concern since many of them are highly vulnerable. About 95 percent of traditional grocery outlets occupy less than 500 SFT space with an asset value of less than Rs. 26600- implying a low capital base providing livelihood for over 40 million of whom about 50 percent are under matriculates(V Sridhar, 2007).

The shift in buying patterns of urban consumers is largely driven by their growing inclination to buy grocery under the same roof in a hygienic and clean environment. Furthermore,wide range of products and brands,multiple payment options such as debit or credit card, food coupons and the like significantly contributed to the growth of modern grocery retailers.

If the rising value in sale of grocery signifies the potential of the sector, the growth in number of outlets across the market show the level of penetration. Table 3(A) and 3(B) show the number of outlets in modern as well as traditional formats during the review and forecast periods respectively:

Table 3(A) shows the number of grocery outlets grown marginally by $3.1 \%$ in traditional format during the study period. Surprisingly the number in modern format had declined by $7.7 \%$. A significant rise in sales coupled with decline in number of outlets in the modern format prompt us to understand that the format is going through a phase of consolidation and moving towards greater efficiency where as stable rise in number of traditional retail outlets show its resilience and deeper levels of penetration. Within modern format a considerable growth in number of hypermarkets reflects the promising size of the segment. It can also be inferred that hypermarkets

Table 3(A). Grocery Retailers Outlets by Channel: Units 2008-2013

\begin{tabular}{lcccccc}
\hline '000 outlets & 2008 & 2009 & 2010 & 2011 & 2012 & 2013 \\
\hline Modern Grocery Retailers & 6.5 & 4.8 & 5.0 & 5.2 & 5.5 & 6.0 \\
- Convenience Stores & 0.8 & 0.8 & 0.8 & 0.7 & 0.8 & 0.9 \\
- Forecourt Retailers & 0.5 & 0.4 & 0.4 & 0.4 & 0.3 & 0.4 \\
-- Chained Forecourt Retailers & 0.5 & 0.4 & 0.4 & 0.4 & 0.3 & 0.4 \\
- Hypermarkets & 0.2 & 0.2 & 0.3 & 0.3 & 0.4 & 0.5 \\
- Supermarkets & 5.0 & 3.3 & 3.5 & 3.8 & 4.0 & 4.2 \\
Traditional Grocery Retailers & 12052.3 & 12158.3 & 12231.9 & 12298.3 & 12360.3 & 12426.5 \\
- Food/Drink/Tobacco Specialists & 2295.3 & 2309.1 & 2320.6 & 2326.8 & 2338.4 & 2352.5 \\
- Independent Small Grocers & 8956.6 & 9041.6 & 9097.2 & 9151.8 & 9197.5 & 9245.3 \\
- Other Grocery Retailers & 800.4 & 807.6 & 814.1 & 819.8 & 824.4 & 828.7 \\
\hline
\end{tabular}

Table 3(B). Forecast Grocery Retailers Outlets by Channel: Units 2013-2018

\begin{tabular}{lcccccc}
\hline '000 outlets & 2013 & 2014 & 2015 & 2016 & 2017 & 2018 \\
\hline Modern Grocery Retailers & 6.0 & 6.4 & 6.8 & 7.2 & 7.7 & 8.1 \\
Convenience Stores & 0.9 & 1.0 & 1.1 & 1.2 & 1.2 & 1.2 \\
Forecourt Retailers & 0.4 & 0.4 & 0.4 & 0.4 & 0.4 & 0.5 \\
Chained Forecourt Retailers & 0.4 & 0.4 & 0.4 & 0.4 & 0.4 & 0.5 \\
Hypermarkets & 0.5 & 0.6 & 0.7 & 0.8 & 1.0 & 1.2 \\
Supermarkets & 4.2 & 4.4 & 4.6 & 4.8 & 5.0 & 5.2 \\
Traditional Grocery Retailers & 12426.5 & 12489.9 & 12550.0 & 12608.0 & 12663.0 & 12716.6 \\
Food/Drink/Tobacco Specialists & 2352.5 & 2368.5 & 2385.8 & 2404.8 & 2426.5 & 2450.7 \\
Independent Small Grocers & 9245.3 & 9288.8 & 9327.8 & 9363.3 & 9393.2 & 9419.5 \\
Other Grocery Retailers & 828.7 & 832.6 & 836.4 & 839.9 & 843.3 & 846.3 \\
\hline Source:http://www.euromonitor.com/grocery-retailers-in-india/reportMay2015 & Euromonitor & International & from \\
trade associations trade press company research trade interviews trade sources & & &
\end{tabular}


are coming up in larger number and making sizeable investments to promote grocery segment as it is a major traffic builder which can be leveraged for cross selling.

\subsection{Triumph of Traditional Grocery Retailers in India}

Traditional grocers remain a dominant force of retailing in India since $60 \%$ to $65 \%$ of the Indian population live in rural areasthat have access only to traditional retail channels for their household shopping needs. Even though modern grocery retail outlets are available in the second-tier and third-tier cities of India,consumers continue to prefer traditional grocery outlets due to the longstanding relationships. Apart from that,informal credit facility,quicker processing- as there is no need to stand in long queues for billing, home delivery without too many conditions attached are some of the factors making buying grocery from traditional retailers more pleasant for the customers. Traditional grocery retailers remained the largest grocery retailers channel in India in 2013 (Table 2(A)) in terms of sales comprising $98 \%$ of total grocery retailers' value sales. This was primarily due to the dominance of independent small grocers- a channel which comprises mostly mom and pop stores.

Nevertheless, growth in traditional grocery retailers slowed down in 2013 due to the growing popularity of hypermarkets and supermarkets in metropolitan areas of India. However this slowdown was minimal and it is clear that the majority of traditional grocery retailers operating in India are well aware of the fact that the channel is likely to remain very important for years to come. Euromonitor International (2015) shows household spending pattern on grocery between modern and traditional formats from 2000 to 2015. It shows a quantum jump in the overall household's spending on grocery $(69.5 \%)$ however the galloping rate of growth witnessed in spending across modern format (13.19 times) can largely be attributed to the very low base value in the beginning year (Table 4).

\subsection{Renaissance of Modern Grocery Retailing in India}

As India is getting more integrated with the world economy, transformation of retail sector especially in urban areas is becoming particularly evident.This was mainly due to the massive expansion of the modern retailers' outlets across the country towards the end of the review period. However the spread of hypermarkets is particularly noticeable in big cities with consumers in smaller cities tending to prefer mom and pop stores for quick purchases of small items, although hypermarkets are slowly penetrating these cities as well. India's home-grown supermarkets account for only $2 \%$ of food and grocery sales and are struggling to make a profit. Revenues have not kept pace with rising rents.

Table 4. Household spending on Grocery during 2000-2015 (Rs per household at constant prices)

\begin{tabular}{lcccccc} 
Spending/Year & 2000 & 2005 & 2010 & 2011 & 2012 & 2015 \\
\hline Grocery retailers' & 39386.3 & 56666.5 & 60814.2 & 61106.7 & 62687.5 & 66748.7 \\
- Modern grocery retailers' & 114.8 & 368.1 & 935.3 & 1033.4 & 1116.7 & 1629.3 \\
-- - Convenience stores' & 21.3 & 29.8 & 58.2 & 66.9 & 65.2 & 61.6 \\
-- Forecourt retailers' & 0.1 & 7.8 & 6.6 & 7.8 & 7.6 & 7.2 \\
-- Hypermarkets' & - & 89.7 & 487.3 & 545.9 & 603.3 & 825.0 \\
-- Supermarkets' & 93.4 & 240.8 & 383.2 & 412.8 & 440.6 & 735.5 \\
Traditional grocery retailers' & 39271.5 & 56298.4 & 59878.9 & 60073.3 & 61570.8 & 65119.4 \\
-- Food/drink/tobacco specialists' & 7974.0 & 9271.8 & 9129.3 & 9284.9 & 9823.5 & 11511.8 \\
-- Independent small grocers' & 29124.5 & 44987.3 & 48715.5 & 48665.2 & 49464.5 & 50789.1 \\
-- Other grocery retailers' & 2173.1 & 2039.3 & 2034.1 & 2123.2 & 2282.8 & 2818.5 \\
\hline Source: http://www.euromonitor.com/grocery-retailers-in-india/report May 2015 National statistics Euromonitor \\
International 2015
\end{tabular}


The article appeared in The Economist (2014) deserves a mention here: "bet made by the chains was that- as India became richer, its consumers would abandon kerbside stalls and mom and pop storesfor air-conditioned stores with wide aisles and broad ranges. Why has it not paid off? In large part it is because supermarkets are not a compelling draw in terms of price and service. Most shoppers in India buy dairy products vegetables and fruit either daily or every two to three days and the traditional trade has a lock on these frequent purchases according to research by the Boston Consulting Group". Mareena Mathew, a faculty member in a leading B-school in Bangalore points that "I rely on my age old neighborhood grocer who is modern enough to take my order over phone and deliver the same in less than half an hour; and I don't even need to look for the so called online grocers who deliver the customer orders as per predetermined slots which may or may not be available all the time".

The study entitled "Dynamics of Organised Retailing in Bangalore with reference to Fresh Fruits Vegetables and Food Products" (Meena \& Ramachandra, 2014) found that the pricing policies were very similar among the majority of the modern and traditional players. However the customer service product range availability of branded products on offer outlet location and design are some of the key differentiators of modern and traditional grocery retailers. Modern establishmentsare bestowed with the ability to offer a far wider variety of both brands and products and they are generally much bigger in size and tend to be positioned in more affluent neighbourhoods. Additionally they tend to offer superior loyalty schemes in comparison with traditional grocery retailers.

Senguptha, (2008) contend that emergence of modem retail in India is not just a result of increasing consumer buying power - manufacturers and unorganized retailers also have an important role to play in this process at the macro-level. At the micro-level the trigger came from diverse angles like entrepreneurial desire to provide better service to consumers social desire to provide relief to the masses in the form of lower prices and a desire to capitalize on emerging business opportunities being provided by the changing business environment.

\section{Grocery Retailing in India- Future Outlook}

Fashion and food will dominate future retailing. The US $\$ 7$ billion Indian food industry, which forms about 45 per cent of the entire FMCG sales, is growing at $10 \%$, ensuring a stable industry which can considerably influence consumption pattern of society and likely to change the market shares of the different types of sellers (Sreejit D. Jagathy Raj VP, 2007).The gradual shift towards modern format is set to redefine the grocery retailing business in India over the forecast period,as it is expected to provide Indian consumers the much touted complete shopping experience under one roof. Debajani \& Hari (2008) suggest that modern retail giants should take advantage of changing retail buying patterns and influence the Indian consumer (consumption oriented increasingly younger population) and the evolution of Indian retail industry from entertainment and convenience to wholesome shopping experience and efficiency.

As the lifestyle of India's urban population is becoming increasingly fast-paced, the use of the internet for shopping is becoming more popular leading to the possibility that urban Indian consumers may also start experimenting with online grocery retailing in order to make the entire household shopping process faster and more efficient. However as many consumers in India especially those living in suburban and rural areas continue to prefer to shop for fresh food and vegetables on a daily basis the strong growth expected in internet retailing will not necessarily be transferred to grocery retailers. The internet retailing of grocery products remained negligible in India at the end of the review period. Online grocers such as bigbasket.com and naturesbasket.com are becoming popular among India's urban consumers although they have a very small consumer base. Growth in this area is restricted due to low level of internet penetration and lack of awareness and trust that major chunk of consumers have in these websites as they are more targeted at niche segments. As "Digital India" campaign picks up momentum and availability of high speed internet connectivity is very much in the offing, the major transformation in online grocery retailing is not ruled 
out.Traditional grocery retail revenue is set to increase in constant value at a CAGR of $1 \%$ over the forecast period a much slower rate of growth than the $15 \%$ constant value CAGR expected in hypermarkets or the $9 \%$ constant value CAGR expected in supermarkets over the forecast period (Euromonitor International 2015).

The story so far and the glimpse of the near future, in terms of growth in grocery sales across the formats, number of outlets and retail space, is depicted in the following Table 5 and Figure 5.

Table 5 and subsequent figure illustrate the growth trajectory of grocery retailing in India 2008-13, and projected trend during 2013-18, which suggests a sustained growth of modern grocery retailing in the time to come. The customers tend to have better experience while buying grocery as the retail space is expected to enlarge from $4.8 \%$ to $9.8 \%$, despite the lesser growth rate is projected as to number of outlets.

\section{Conclusion}

The analysis of data and review of relevant literature suggests that the evolution and patterns of the diffusion process of modern food retail industry has significant implications for India. The data analysed in this paper provide ample evidence that the money spent on grocery is increasing andthere is enough scope and space for everyone to serve and flourish.Ultimately it is the value (for money) convenience and varieties of

Table 5. Growth rates of modern vis-a-vis traditional grocery retailing in India

\begin{tabular}{|c|c|c|}
\hline $\begin{array}{l}\text { Format/ Growth rate } \\
\text { in } \%\end{array}$ & $2008-13$ & 2013-18 \\
\hline \multicolumn{3}{|c|}{ Modern grocery retail } \\
\hline Sales value & 76.2 & 75 \\
\hline No of outlets & -7.7 & 35 \\
\hline \multicolumn{3}{|c|}{ Traditional grocery retail } \\
\hline Value & 68 & 2.73 \\
\hline No of outlets & 3.1 & 2.33 \\
\hline \multicolumn{3}{|c|}{ Total grocery retail } \\
\hline Value & 69 & 4 \\
\hline No of outlets & 3.1 & 2.35 \\
\hline Retail space & 4.8 & 9.8 \\
\hline
\end{tabular}

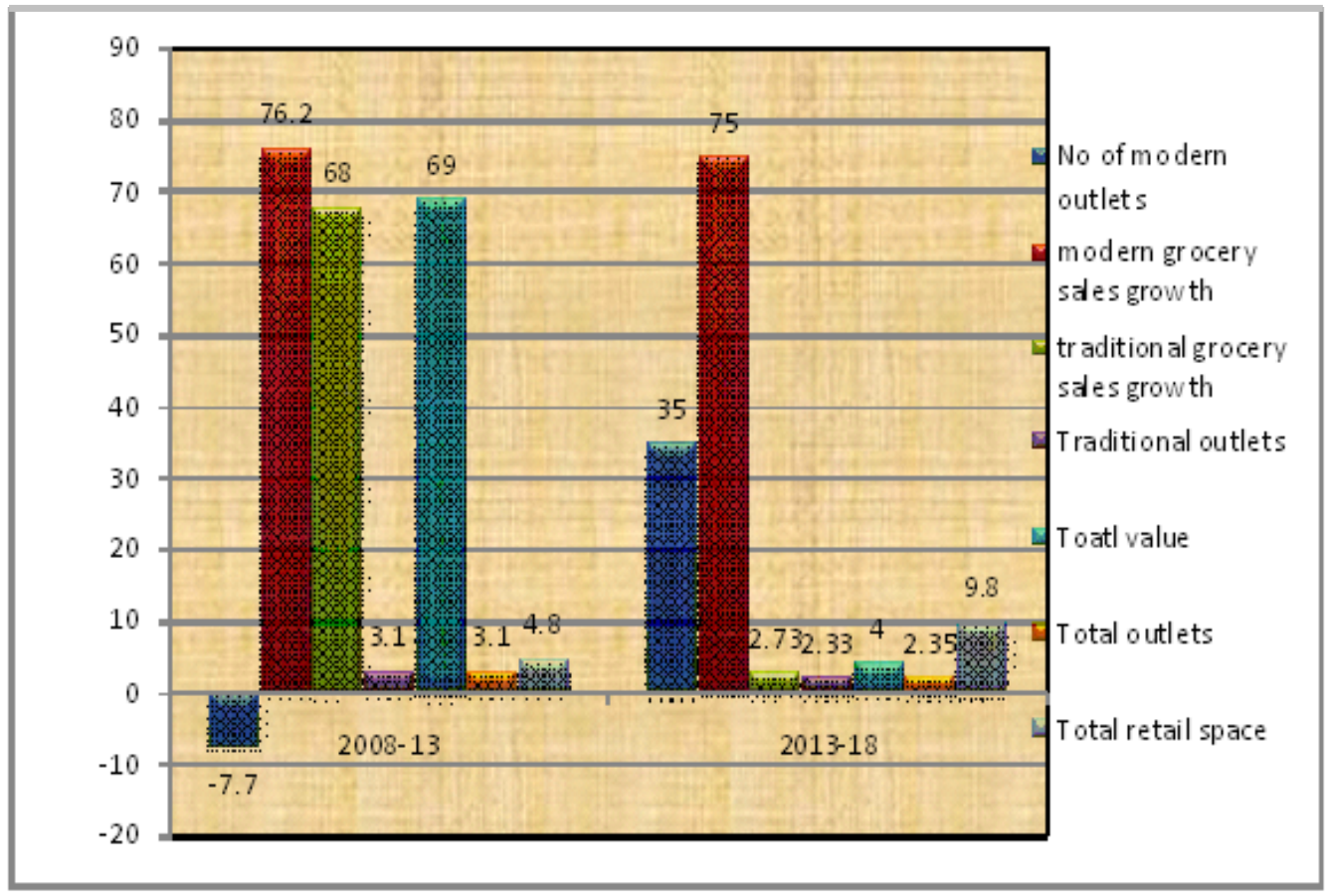

Figure 1. Growth rates of Modern vis-à-vis traditional grocery retailing. Source: Table 5 
products made available that hold the key for a gaining and retaining the customer base in the highly competitive landscape.

The bright forecast for the modern retailers should leave no room for complacency since the competition only gets more intense and the customers tend to be more demanding and discerning than ever before. As the seemingly mature traditional grocery retailing is not expected to grow significantly, the small retailers should learn to keep pace with the changing times and upgrade themselves in terms of technology adoption customer service and the like. There is a need to revamp and restructure the traditional way of procurement and retailing of grocery which calls for substantial investment for expansion and modernization.

The proposal of current central government to provide access to formal credit to small and marginal establishments should be effectively implemented to sustain and strengthen the small retailers. At the macro level the market needs both a growing and vibrant modern retail format and a mature traditional format to cater to the growing needs of the diverse segments.

\section{Acknowledgement}

The authors sincerely acknowledge $\mathrm{Mr}$ Manish Raval, Client Development - Travel, Government and Academics, Euromonitor International for providing access to the country data, which largely was the source of secondary data.

The authors express deep sense of gratitude to Senior Assistant Professors of XIME, Bangalore-Dr John Ben, Dr Bhavani Akkapeddi and Mr Indraneel Ganguly for their valuable inputs. The authors put on record the deepest thankfulness for the time taken, and the valuable comments and suggestions given by the learned reviewers to shape this article well.

\section{References}

Basker, E. (2005). Job Creation or Destruction? LaborMarket Effects if Wal-Mart Expansion. The Review of Economics and Statistics. 87, 174-183.
Batt, P. J., \& Cadilhon J. J. (2007). Proceedings of the International Symposium on Fresh Produce Supply Chain Management. Edited by Batt Peter J. and Cadilhon Jean-Joseph. RAP Publication 2007/21. Bangkok: AFMA Curtin University Department of Agriculture FAO

Blose, J., Tankersley, W. B., \& Flynn, L. R. (2005). Managing Service Quality Using Data Envelopment Analysis. Quality Management Journal. 12(2), 7-24.

Debajani., \& Hari, G. M. (2008). Organised Retail in India: A Case Study of Bal-Wart. Indian Journal of Marketing, $38,35-44$.

Earnst \& Young Flavours of incredible India Opportunities in the food industry. Retrieved from http://www.cifti.org/ Reports/Flavors\%20of\%20Incredible\%20India\%2009. pdf on $20^{\text {th }}$ May 2015.

Fernandes, M., et al. (2000). India's Retailing Comes of Age. Mckinsey Quarterly, (4), 94-102.

Goetz, S. J., \& Swaminathan, H. (2006). Wal-Mart and Countrywide Poverty. Social Science Quarterly, 87(2), 211-226.

Goswami, P. (2009). Would Kiranas in Urban India Survive the Modern Trade Onslaught? Insight from Efficiency Perspective Advances in Consumer Research - AsiaPacific Conference Proceedings, pp. 8344-8345.

Holsi, H. P. (2009). Traditional and Modern Grocery Retailing In Malaysia. Retail Digest, 22-29.

Kakkar, S. (2008). The Future of Kirana Stores and Implications for National Brands, 9 $^{\text {th }}$ Marketing and Retail Conclave Organized by Technopak February 19-21, The Taj Palace New Delhi India.

Kalhan, A. (2007). Impact of malls on small shops and hawkers. Economic and Political Weekly, pp. 2063-2066.

Mandhachitara, R., \& Santimauro, F. (2011). Sustaining Traditional Grocery Store Formats in an Increasingly Modern Trade Shopping Environment. Proceedings of the Northeast Business \& Economics Association. pp. 286-294. ISSN: 1936203X.

Mathew, J., et al. (2008). Impact of Organized Retailing On The Unorganized Sector Indian Council for Research on International Economic Relations May. Retrieved from http://dipp.nic.in/english/publications/reports/icrier report_27052008.pdf on $1^{\text {st }}$ December 2014.

Meena, R. N. (2014). Dynamics of Organised Retailing in Bangalore with Reference to Fresh Fruits Vegetables and Food Products Jawaharlal Nehru Technological University Hyderabad Unpublished manuscript.

Peter, J. B., \& Jean-Joseph, C. (2006). Proceedings Of The International Symposium On Fresh Produce Supply 
Chain Management Lotus Pang SuanKaeo Hotel Chiang Mai Thailand December.

Richa, J. (2011). Organized Retailing and its Effect on Grocery Stores with Special Reference to Kota City. Journal of Marketing \& Communication. 6(3), 21-29.

Sadaf, S., \& Shyama, K. (2010). Delighting the Customers' Senses - Key to Store Differentiation. Indian Journal of Marketing Number, 40(6).

Sanghvi, N. (2007). I have seen the future and it works. The Economic Times, Kolkata Edition, pp. 4.

Shaik, S. B. (2009). The Economic Impact of Department Stores on Small Vendors in Kurnool District Andhra Pradesh. Indian Journal of Marketing, 39.

Shankar, G., \& Priya, S. (2009). Corporate Retail: Dangerous Implications for India's Economy. Economic and Political Weekly, 44.

Sobel, R. S., \& Dean, A. M. (2006). Has Wal-Mart Buried Mom and Pop?: The Impact of Wal-Mart on Self Employment and Small Establishments in the United States. Retrieved from www.be.wvu.edu/divecon/econ/ sobel/WalMart/Walmart.pdf last accessed on 23.2.07.

Som, A. J. (2012). An Empirical Study on Factors Influencing Store Image, Satisfaction and Loyalty in Department Stores. Graphic Era University, Dehradun Unpublished manuscript. Retrieved on 20 $0^{\text {th }}$ May 2015 from http:// shodhganga.inflibnet.ac.in// handle/10603/5132.

Sreejit, D. \& Jagathy, R. V. P. (2007). Organized Retail Market Boom and the Indian Society. International Marketing Conference on Marketing \& Society, IIMK 8, 1.

Sridhar, V. (2007). Retail Invasion Front Line, 24(13), 13.

The Economist. (2014). Modern food retailing has struggled to win customers from India's old-fashioned merchants. Retrieved from http://www.economist.com/news/ business/21625799-modern-food-retailing-has-struggled-win-customers-indias-old-fashioned-merchantslong on $20^{\text {th }}$ May 2015.

Vijay, K., et al. (2008). Organised Food Retailing: A Blessing or a Curse?. Economic and Political Weekly, 43.

Vijaya, D. P. V. (2007). The spread of Organized Retailing in India-with a special Reference to Vijayawada City. Indian Journal of Marketing. 37, 3-9.
Vijayraghavan, K., \& Ramsurya, M. V. (2007) Mom and pop happy letting a rich tenant take over. The Economic Times. pp. 4.

Wal-Mart, W. (2005). Grand Opening: With a New Store Opening Nearly Every Day What is Wal-Mart's Impact on America's Small Businesses?. Wal-Mart Watch: Low Prices at What Cost? Wal-Mart Watch Annual Report Center for Community and Corporate Ethics. pp. 10.

\section{Notes}

Forecast value data shown in Table 2(B) is in constant terms

\section{About the Author}

Dr N. Meena Rani is an engaged academician and researcher, and is inclined to explore the areas of retailing and advertising from marketing, socio-economic and ethical perspectives, and is concerned with policies affecting public interest. She obtained M.Phil in Ethical Issues in Advertising from Bharatidasan University, and Ph.D in Organised Retailing from Jawaharlal Nehru Technological University, Hyderabad. She has published articles in national and international journals, and presented papers in conferences hosted by leading national and international institutions.

Dr K. Ramachandra is a dedicated academician and extensively engaged in research and publications. He had obtained Ph.D from Bangalore University and authored over 25 titles for UG and PG programs in Commerce and Management, Bangalore University and MBA program in Visweswaraiah Technological University. He guided over 30 Ph.D and 100 M.Phil projects from various leading universities in south India. 